\title{
An Implementation and Comparative Analysis of PID Controller and their Auto Tuning Method for Three Tank Liquid Level Control
}

\author{
Farhad Aslam \\ Department of Electrical \& Instrumentation \\ Engineering \\ Thapar University, Patiala, Punjab, India
}

\author{
Mohd. Zeeshan Haider \\ Department of Electrical and Instrumentation \\ Engg. \\ Thapar University, Patiala, Punjab, India
}

\begin{abstract}
In industrial control systems the liquid level is carrying its significance as the control action for level control in tanks containing different chemicals or mixtures is essential for further control linking set points. The three level control models are considered in our work. In conventional model for three tank liquid level, the control is done with conventional control PID model. The auto tuning technique of PID controller is adopted for more reliable and precise control action which incorporate the uncertain factors also. In this work the comparison of the conventional PID and auto tuning is clarified.
\end{abstract}

Keywords: PID Control, Three tank level, Auto Tuner Chemical Concentration, CSTR

\section{INTRODUCTION}

In industrial applications liquid level control is very important as in food processing industry, dairy, filtration, effluent treatment, nuclear power generation plants, pharmaceutical industries, water purification systems, industrial chemical processing and spray coating and boilers in all the industries. The typical actuators used in liquid level control systems include pumps, motorized valves, on-off valves and level sensors such as displacement float, capacitance probe and pressure sensor provide liquid level measurement for feedback control purpose so that as per the process requirements the fluids could be controlled. In this exercise, the system is modeled, calibrated, and controlled for level determination in a three tank level control system. In particular, this exposes the fundamental modeling principle of fluid mass balance, pressure sensor calibration, and a feedback control design methodology for a state-coupled, three-tank level control system.

The level control is a type of control method for common in process system. It must be controlled by the proper controller. The objective of the controller in the level control is to maintain a level set point at a given value and be able to accept new set point values dynamically. The conventional proportional-integral-derivative (PID) is commonly utilized in controlling the level, but the parameter is not enough for efficient control

This paper endeavors to design a system using two methods of auto tuning of PID parameters called Basic design mode and Extended design mode. Auto tuning is basically used to tune PID gains automatically in a Simulink model containing a PID controller block. The PID tuner allows to achieve a good balance between performance and robustness. It automatically computes a linear model of the plant. The PID tuner considers the plant to be the combination of all blocks between the PID controller input and output. Thus, the plant includes all blocks in the control loop, other than the controller itself. The main objectives of PID tuner are closedloop stability (in which system output remains bounded for bounded input), adequate performance (in which closed- loop system tracks reference changes and suppresses disturbance as rapidly as possible) and adequate robustness (the loop design has enough gain margin and phase margin to allow for modeling errors or variations in system dynamics.

Basic design mode of PID tuner refine the controller design by adjusting response time. It make the closed- loop response of the controlled system faster or slower. Extended design mode of PID tuner refine the controller design by separately adjust loop bandwidth and phase margin. The larger the loop bandwidth, the faster the controller responds to changes in the reference or disturbances in the loop. The larger the phase margin, the more robust the controller is against modeling errors or variations in plant dynamics. The objective of this paper is to show that by employing the proposed tuning of PID controllers, an optimization can be achieved. This can be seen by comparing the result of the PID tuner against the conventional PID controller.

\section{CASE STUDY}

In the considered case study, two steams, $\mathrm{A}$ and $\mathrm{B}$, are mixed in three series tank, and the output concentration of component $\mathrm{A}$ is controlled by manipulating the flow of stream A . Here we consider step change to the set - point, these changes represent the situation in which the plant operator occasionally changes the value and allows a considerable time for the control system to respond. It is shown in fig 1 .

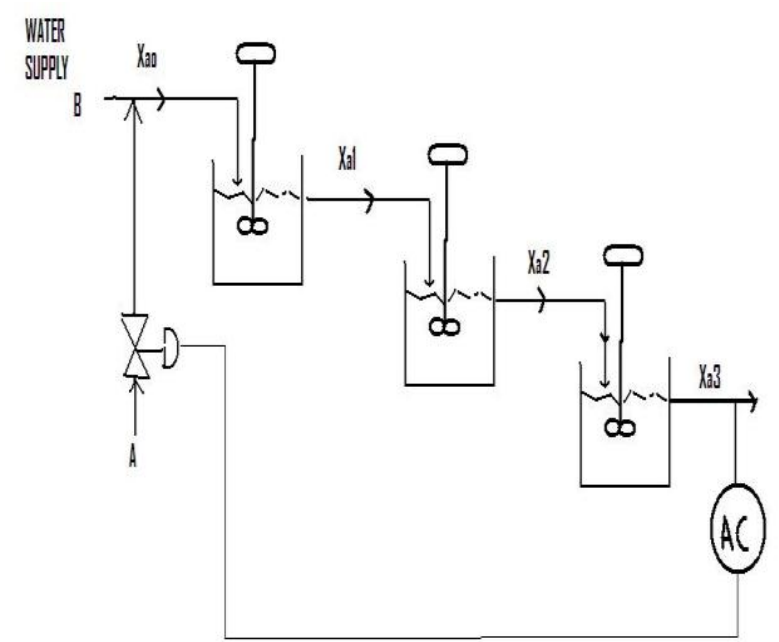

Fig.1: Three tank liquid level process 
The tanks are named tank A, tank B and tank $\mathrm{C}$ respectively from top to bottom. Tank ' $\mathrm{C}$ ' serves merely as a reservoir. Two proportional control valves are used to regulate the flow between each tank. Valve 1 is located between tank 'A' and tank ' $B$ ', which controls the inlet mass flow to tank ' $B$ '. Valve 2 is located between tank ' $B$ ' and tank ' $C$ ', which controls the outlet mass flow from tank ' $\mathrm{B}$ '. A level sensor is mounted at the bottom of tank ' $C$ ' to measure the water height inside the tank. The three tank level control with liquid in it shown in fig. 1 .The design model consist of a controller that will either maintain that liquid level at a desired point, a disturbance rejection problem ,or one that can be used to move the level set- point . The idea is to fill the tank to the desired set- point as quickly and smoothly as possible. The amount of overshoot I minimized and during the time when the tank has a level greater than the set point value before it finally settle down, the current level at any time $\mathrm{T}$ is designated as $\mathrm{h}$. The additional liquid flows out of the tank through an open valve. This flow is represented by q. Liquid is allowed to flow into the tank by mean of pump. The pump flow, Q, can be regulated by controller. The tank cross -sectional area is represented by $\mathrm{A}$.

The mass balance equation for liquid in the tank as a function of time

$A \frac{d h}{d t}=Q-q$

Flow out of the tank , q , through the outlet pipe and the valve is described by

$$
Q_{c}=\Phi A_{p}(2 g h)^{0.5}
$$

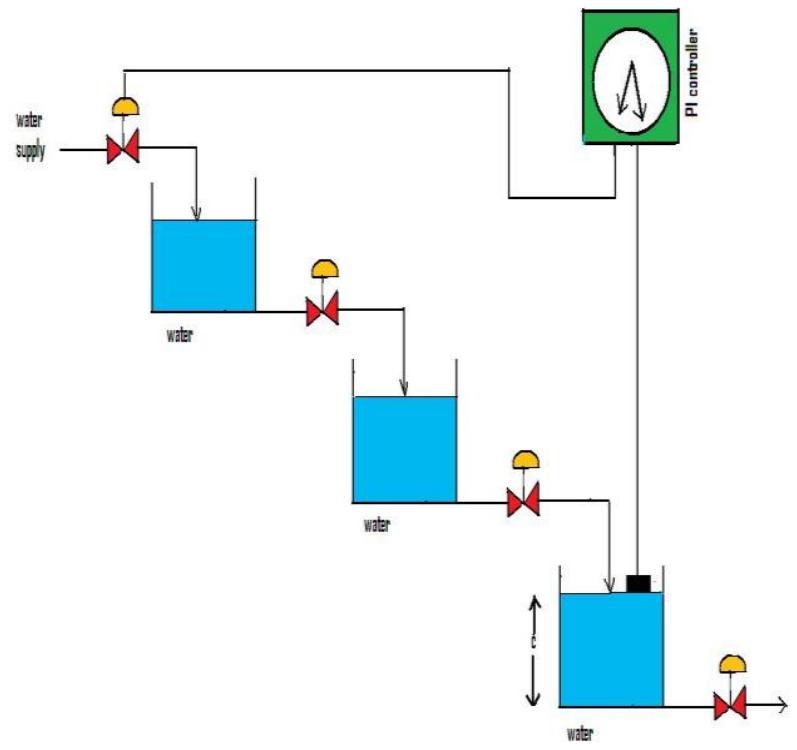

Fig.2: Three tank liquid level control

\section{PROBLEM FORMULATION}

Three tank system describe here is real experiment that tank are numbered from left to right in the fig. (2) as tank 'A' , tank ' $\mathrm{B}$ ', and tank ' $\mathrm{C}$ '. All three tanks are connected, with the third tank in the series, tank 2 draining to the exit. Liquid is pumped into the first and the third tanks to maintain their levels. The levels in the first and third tanks control the level in the middle tank The level in the middle tank affects the levels in the two end tanks. The system is described by the differential equation

$$
\begin{aligned}
& A \frac{d h_{a}}{d t}=Q_{1}-q_{a} \\
& A \frac{d h_{b}}{d t}=q_{a b}-q_{b c} \\
& A \frac{d h_{c}}{d t}=Q_{2}+q_{b c}-q_{c} \\
& Q_{a b}=\Phi_{a} A_{p} \operatorname{Sign}\left(h_{a}-h_{b}\right) * 2 g\left(2 g l h_{a}-h_{b} l\right)^{0.5} \\
& Q_{b c}=\Phi_{b} A_{p} \operatorname{Sign}\left(h_{b}-h_{c}\right) * 2 g\left(2 g l h_{b}-h_{c} l\right)^{0.5} \\
& Q_{c}=\Phi_{c} A_{p}\left(2 g l h_{a}-h_{b} l\right)^{0.5}
\end{aligned}
$$

The transfer function of three tank are represented as

$$
\frac{C(s)}{M(s)}=\frac{0.55}{(2 s+1)(s+1)^{2}}
$$

\section{SIMULATION, RESULTS COMPARISONS \\ Our Design requirement}

Maximum Overshoot $=<1 \%$

Undershoot $=0$

Rise time $\left(\mathrm{t}_{\mathrm{r}}\right)=<2.5 \mathrm{sec}$

Settling time $\left(t_{\mathrm{s}}\right)=<3.5 \mathrm{sec}$

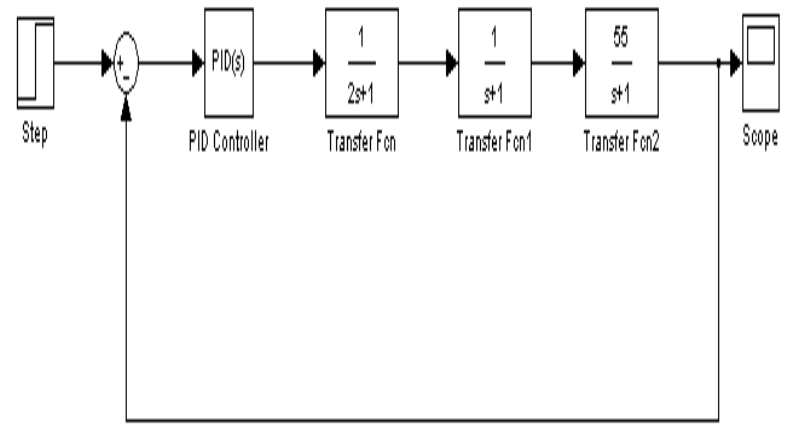

Fig. 3: Process model with PID controller (Conventional)

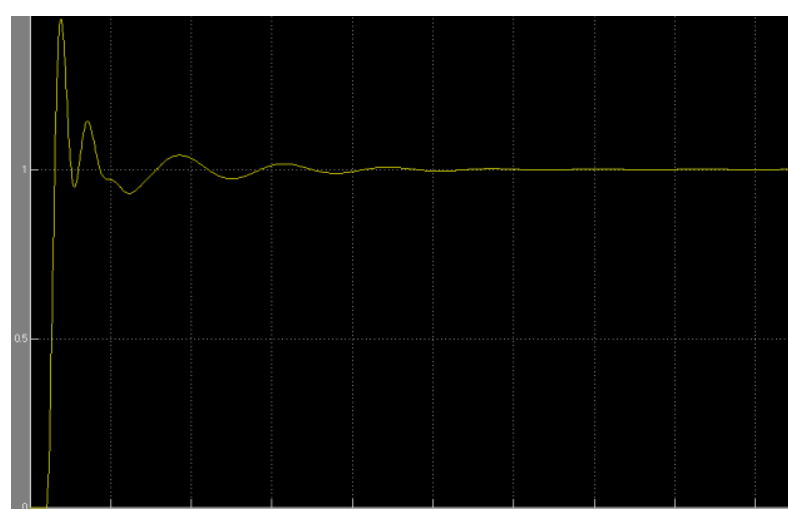

Fig. 4: System output with PID controller (Conventional) 


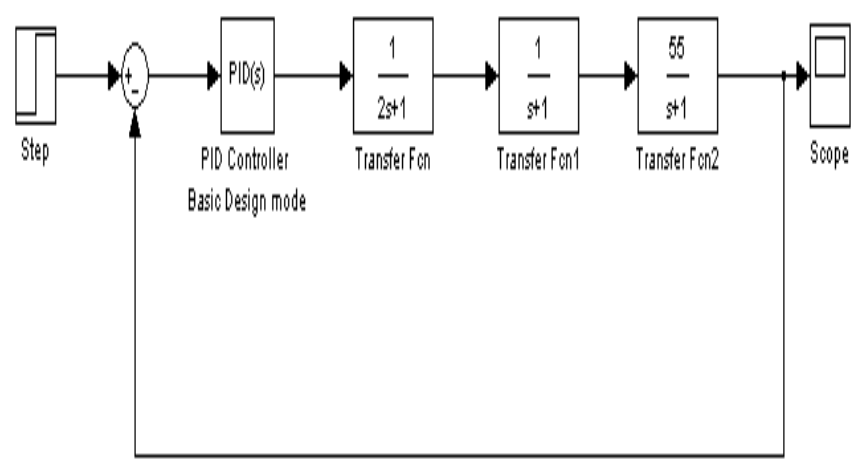

Fig. 5: Process model with PID controller (Basic Design mode)

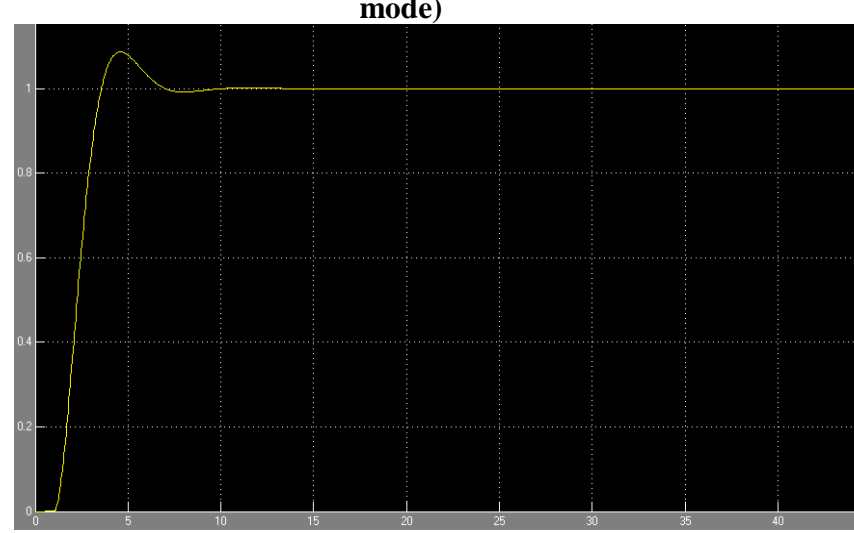

Fig. 6: System output with PID controller (Basic Design mode)

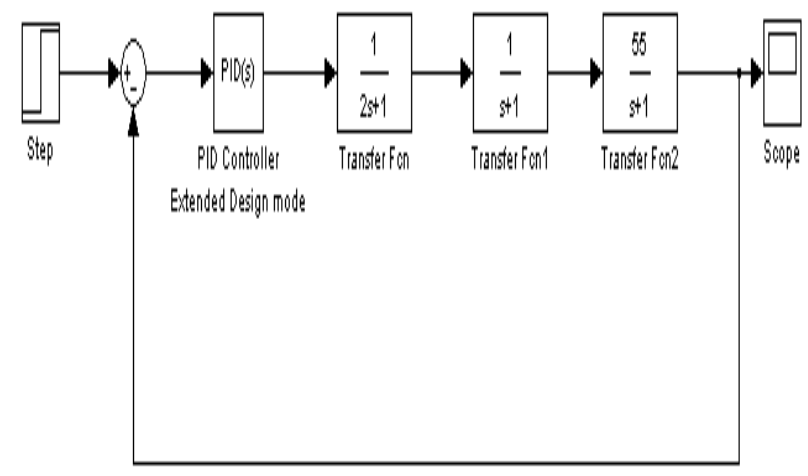

Fig. 7: Process model with PID controller (Extended Design mode)

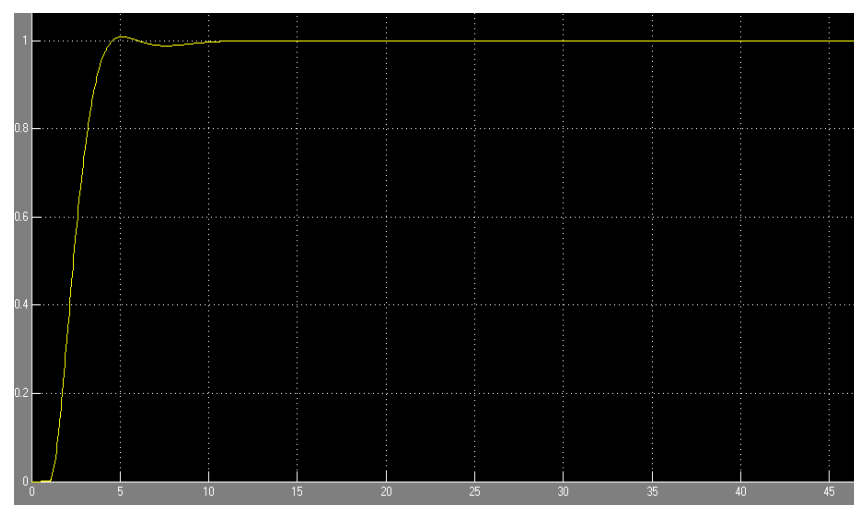

Fig. 8: System output with PID controller (Extended Design mode)

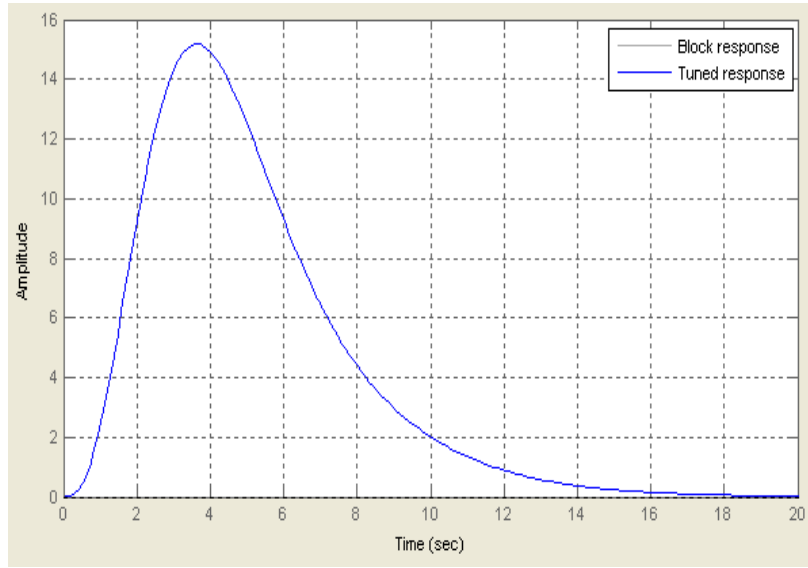

Fig.9: Step disturbance rejection plot with PID controller auto tuning (Extended design mode)

So, based on the above results a comparison table is drawn of.different methods of PID controller which is shown in table 1. In this table it can be seen that our design requirement is achieved in the Extended design mode of the PID controller

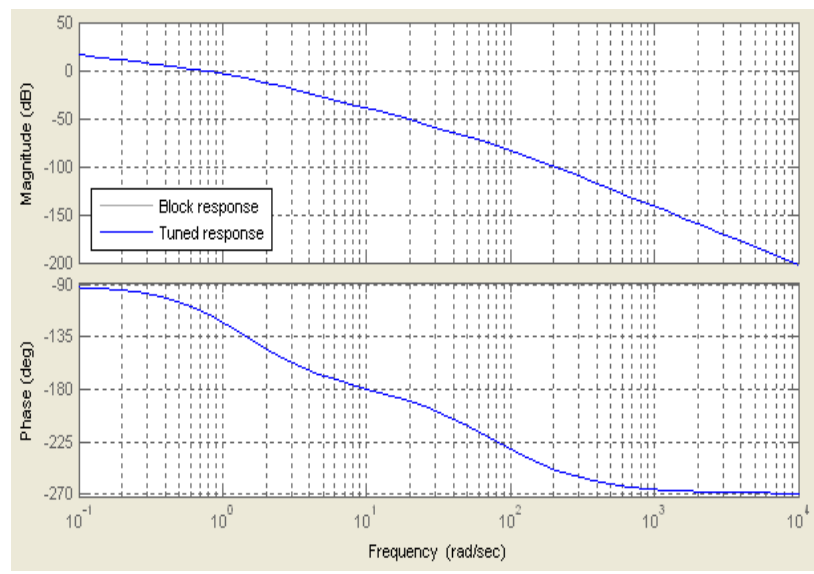

Fig. 10: Open- loop Bode plot with PID controller auto tuning (Extended design mode) 
Table 1: Comparative analysis of different tuning methods of PID controller

\begin{tabular}{|c|c|c|c|c|c|c|c|}
\hline $\begin{array}{l}\text { Controller } \\
\text { Types }\end{array}$ & $\mathbf{K}_{\mathbf{P}}$ & $\mathbf{K}_{\mathbf{I}}$ & $\mathbf{K}_{\mathbf{D}}$ & $\begin{array}{l}\text { Rise } \\
\text { time } \\
\left(t_{r} \text { in }\right. \\
\text { sec })\end{array}$ & $\begin{array}{l}\text { Settling } \\
\text { time } \\
\left(t_{\text {s in sec }}\right)\end{array}$ & Overshoot $(\%)$ & Undershoot $(\%)$ \\
\hline $\begin{array}{l}\text { PID } \\
\text { (Conventional) }\end{array}$ & 0.2 & 0.5 & 0.5 & 0.346 & 12.3 & 44.5 & 10 \\
\hline $\begin{array}{l}\text { PID } \\
\text { (Basic Design } \\
\text { mode) }\end{array}$ & 0.05215 & 0.01602 & 0.04198 & 1.71 & 5.32 & 8.66 & 0 \\
\hline $\begin{array}{l}\text { PII } \\
\text { (Extended } \\
\text { Design mode) }\end{array}$ & 0.04354 & 0.01214 & 0.03872 & 2.1 & 3.22 & 0.895 & 0 \\
\hline
\end{tabular}

\section{CONCLUSION}

When implementation of the conventional PID controller is done to the process, it generates a very large overshoot together with undershoot. This is not the desired requirement. So after implementing auto tuner of PID controller, it can be seen that both overshoots and undershoots are reduced to a greater extent as compared to the conventional PID control. Finally the optimization is achieved in the Extended design mode of the PID controller. The tank level control is such a process which is perhaps more often used in all industrial processes including electrical, petroleum industry, power sectors, development sites, paper industry, beverages industry, etc. so the controlled stable operation of this drive attracts the researchers always, still keeping more and more future scope in it.

\section{REFERENCES}

[1] Yun Li,Kiam Heong Ang and Gregory C.Y.Chong, "PID Control System Analysis and Design - Problems, Remedies, and Future Directions". IEEE control system magazine, February 2006 pp. 32-41,2006

[2] Fried land B., "Advanced Control System Design", Prentice Hall, New Jersey, 1996.

[3] Yung C. Shin, Chengying $\mathrm{Xu}$ "Intelligent Systems: Modeling, Optimization, and Control" CRC Press 2009.
[4] Madlová, A., Antoová, M., Baráthová, M., Polakoviè, M., Otefuca, V., and Bále ${ }^{1}$, V., Chem. Pap. 53, 366 (1999).

[5] K.J. Astrom, \& T. Hagglund, "The future of PID control Control Engineering Practice”, pp.1163 -1175. 2001.

[6] Rajani K. Mudi, Chanchal Dey, \& Tsu - Tian Lee, "An improved auto - tuning scheme for PI controllers", Journal of science Direct ISA Transactions, 47: 45 - 52, 2008 .

[7] Luis E. Zarate, Peterson Resende, \& M. Benjamin," A Fuzzy Logic and Variable Structure Base Controller for CSTR Control". Annual conference of IEEE, 2001.

[8] Xiao-Feng Li, Jian Sun, Hui-Yan Wu, Wei-Dong Zong, "Application of the fuzzy PID to the Power Plant", IEEE 2007.

[9] Schmidt, Lanny D. (1998). The Engineering of Chemical Reactions. New York: Oxford University Press. ISBN 019-510588-5

[10] Steven T.Karris, 'Introduction to Simulink with Engineering Applications', Orchard Publications, www.orchardpublications.com 